\title{
Application Article \\ Optimized Ultrawideband and Uniplanar Minkowski Fractal Branch Line Coupler
}

\author{
Mohammad Jahanbakht ${ }^{1}$ and Mohammad Tondro Aghmyoni ${ }^{2}$ \\ ${ }^{1}$ Department of Electronic Engineering, Shahr-e-Qods Branch, Islamic Azad University, Tehran, Iran \\ ${ }^{2}$ Institute of Postgraduate Studies, Multimedia University, Selangor, 63100 Cyberjaya, Malaysia
}

Correspondence should be addressed to Mohammad Jahanbakht, mjahanbakht@yahoo.com

Received 17 May 2012; Accepted 27 July 2012

Academic Editor: Renato Cicchetti

Copyright ( 2012 M. Jahanbakht and M. Tondro Aghmyoni. This is an open access article distributed under the Creative Commons Attribution License, which permits unrestricted use, distribution, and reproduction in any medium, provided the original work is properly cited.

\begin{abstract}
The non-Euclidean Minkowski fractal geometry is used in design, optimization, and fabrication of an ultrawideband (UWB) branch line coupler. Self-similarities of the fractal geometries make them act like an infinite length in a finite area. This property creates a smaller design with broader bandwidth. The designed $3 \mathrm{~dB}$ microstrip coupler has a single layer and uniplanar platform with quite easy fabrication process. This optimized $180^{\circ}$ coupler also shows a perfect isolation and insertion loss over the UWB frequency range of $3.1-10.6 \mathrm{GHz}$.
\end{abstract}

\section{Introduction}

Recently, ultrawideband technology has been used in many branches of science and wide range of applications such as radars, navigation, telemetry, mobile satellite communications, biomedical systems, the direct broadcast systems, and remote sensing utilities. The design of an appropriate microwave device for these systems is one of the major challenging tasks.

Microstrip power divider and coupler designs and topologies which achieved compact size and broadband operation of the component could be categorized in some major methods including

(a) wideband stub matching,

(b) multistaging of the ordinary components,

(c) multilayer and multiwafer packaging technologies,

(d) deforming the shapes and using alternative geometries.

As an instance of the first category, a $3 \mathrm{~dB}$ power divider on microstrip line is analyzed and designed in [1] using UWB stub matching technique. This divider is formed by installing a pair of stepped-impedance, open-circuited stubs, and parallel-coupled lines to two symmetrical output ports.
Also in this class, an UWB microstrip power divider with good isolation and sharp roll-off skirt is proposed in [2]. By introducing a pair of quarter-wavelength shortcircuited stubs and parallel-coupled lines to 2 symmetrical output ports, good performance in terms of equal power splitting is achieved. By virtue of direct-current chocked and half-wavelength transmission zeros of short-circuited stubs, out-of-band roll-off skirt near the cutoff frequencies is sharpened.

Multistaging of the well-known Wilkinson power divider is used in [3] to achieve an UWB coplanar waveguide balun for operation over 800-5000 MHz. Another well-established example of the multistaging method is proposed in [4]. Thereby, an optimized microstrip 3-stage Wilkinson power divider based on lowpass filter is presented. The particle swarm optimization method and method of moment have been used to broaden the bandwidth to effectively cover 1$8 \mathrm{GHz}$ which is equal to $155.6 \%$ fractional bandwidth.

Multistaging of the T-junctions in slot line topology has also been presented in [5]. This compact and out-of-phase uniplanar power divider operates over the ultra wideband frequency range.

The third alternative category is to use multilayer substrates. A multilayer in-phase power divider with ultrawideband behavior is presented in [6]. The proposed divider 


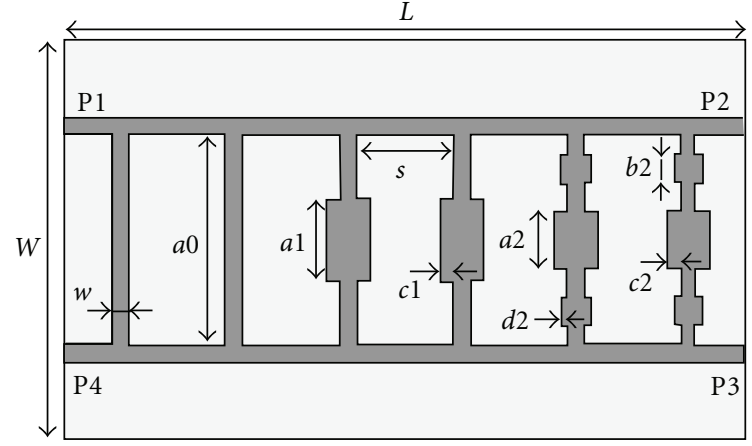

FIGURE 1: Profile of the UWB microstrip branch line coupler which consists of $2 \times$ ordinary, $2 \times$ first-order, and $2 \times$ second-order Minkowski fractal branches.

TABlE 1: Topology and widebanding techniques comparison between $3 \mathrm{~dB}$ couplers and power dividers.

\begin{tabular}{lcc}
\hline Reference number & Transmission line & UWB technique \\
\hline$[1]$ & Microstrip & Wideband stub matching \\
{$[2]$} & Microstrip & Wideband stub matching \\
{$[3]$} & CPW & Multistage Wilkinson \\
{$[4]$} & Microstrip & Multistage Wilkinson \\
{$[5]$} & Slot line & Multistage T-junctions \\
{$[6]$} & Microstrip & Multilayer substrate \\
{$[7]$} & Parallel strip lines & Multilayer substrate \\
{$[8]$} & Slot line & Multilayer substrate \\
This work & Microstrip & Fractal deformation \\
\hline
\end{tabular}

exploits broadside coupling via a multilayer microstrip slot configuration. The design method is based on conformal mapping techniques.

Two other UWB multilayer power dividers are presented in $[7,8]$. In [7], a low-loss transition from a coaxial transmission line to a double-sided parallel-strip line is presented. On the other hand, a slot line topology with bandpass filtering is used in [8].

The UWB techniques in the references are compared together in Table 1. Most of these works are using microstrip lines and a few others use other alternatives. According to author's survey, usage of fractal geometries is not reported in branch line coupler designs, so far.

Fractal deformation in design and fabrication of an UWB branch line coupler will be demonstrated in the next sections. The Minkowski fractal will be used to redesign an ordinary $3 \mathrm{~dB}$ coupler and broaden its bandwidth. The coupler dimensions are optimized and the final tuned structure is fabricated. The measured and analyzed results will be presented and compared.

\section{Coupler Design and Theory}

Fractals are non-Euclidean geometries with some amazing behaviors and specifications. These geometries have been used in articles to achieve multiband radiation, band width
TABle 2: Proposed coupler dimensions [mm].

\begin{tabular}{cccccccccc}
\hline$L$ & $W$ & $w$ & $s$ & $a 0$ & $a 1$ & $c 1,2$ & $a 2$ & $b 2$ & $d 2$ \\
\hline 45 & 30 & 1.1 & 6.4 & 13.9 & 5.4 & 0.9 & 3.7 & 1.9 & 0.5 \\
\hline
\end{tabular}

broadening, and size reduction [9]. These benefits are actually resulting from curvature's self-similarity, which means these geometries represent a certainly finite area which is bounded in a theoretically infinite line.

The Minkowski fractal is used in this paper to broaden the bandwidth and shrink the size of a branch line coupler. The UWB coupler profile is shown in Figure 1. This coupler possesses four ports where the input power at P1 splits equally between output ports P2 and P3. The 4th port is isolated and terminated using a matched load.

This coupler has 6 branches of parallel lines. Two of them are conventional straight lines and the remaining 4 branches have Minkowski fractals of 1 st and 2 nd orders. When fractal order approaches to infinity, the segment length approaches to zero and the circumference grows boundlessly. Meanwhile, the area still remains finite.

This coupler is mounted on TMM13 Rogers substrate with dielectric constant of 12.80, dielectric loss tangent of 0.002 , and substrate thickness of $1.27 \mathrm{~mm}$. Coupler dimensions are presented in Table 2. These dimensions are initially set to the values of a conventional branch line coupler and then tuned through a simple optimization procedure in ANSOFT HFSS 13.0.

The well-known quasi-Newton optimization method is selected with 500 iterations. Except for L, W, w, s, and a0; all other variables in Table 2 are defined as optimization variables. The goal is set to gain minimum inbound and maximum outbound return losses and also to achieve $3 \mathrm{~dB}$ insertion loss.

As can be seen in Figure 1, in two 2nd-order branch lines, each straight segment of the 1st order should be replaced with order one itself (to enforce self-similarity). This means that the central big square ought to have small squares protruding from each side, while it has not!

The reason is laid beneath optimization. After optimization process, the area and size of these outgrowths get smaller than realizable margins, and therefore omitted from the design.

According to the uniplanar and single-layer structure of the coupler, it has very easy fabrication process. Besides, based on the optimized fractal geometry of the coupler, it owns a compact size and broad bandwidth. These features of the coupler will be studied in the next section.

\section{Results and Discussion}

Hereby some terms have to be suggested for easier understanding of the text. Similar to Figure 1, a conventional branchline coupler consists of 4 ports and 6 branches of straight lines. If someone replaces the 6 ordinary branches with first-order Minkowski fractals, a 1st-order fractal couplerwill be achieved. 


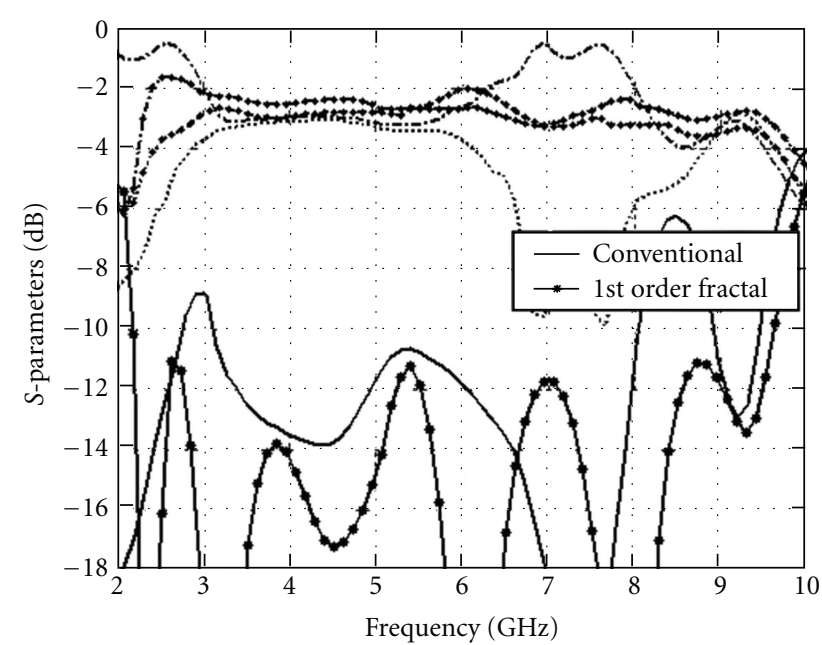

Figure 2: Scattering S11 (-), S21 ( - •), and S31 ( . . ) parameters of the conventional branch line coupler and 1st-order Minkowski branch line coupler.

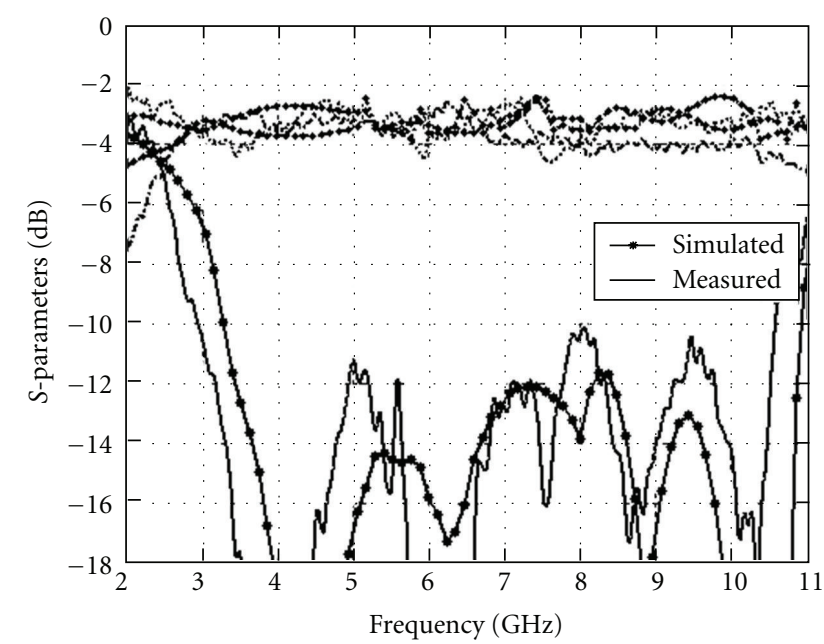

Figure 3: Simulated and measured Scattering S11 (-), S21 (-•), and S31 $(\cdots)$ parameters of the UWB Minkowski branch line coupler.

In Figure 2, scattering parameters of the conventional branch line coupler has been compared with 1st-order fractal. The operating $3 \mathrm{~dB}$ frequency range of the conventional coupler is $3.2-6.2 \mathrm{GHz}$. This bandwidth extended to 2.6$9.5 \mathrm{GHz}$ by using 1 st-order fractal.

As a consequence of Figure 2, one may think of adding extra orders of the same fractal lines to extend the bandwidth. As shown exactly in Figure 1, by adding two 2nd-order lines to the conventional and 1st-order fractal branches, the operating frequency range of the coupler would expand enough to cover the UWB necessity. This property is investigated in Figure 3 where the simulation and measurement results are compared and shown a good agreement.

According to Figure 4, the phase difference at the output ports $\mathrm{P} 2$ and $\mathrm{P} 3$ remains 180 degree over the entire frequency range. Adding extra orders of the fractals has no major effect

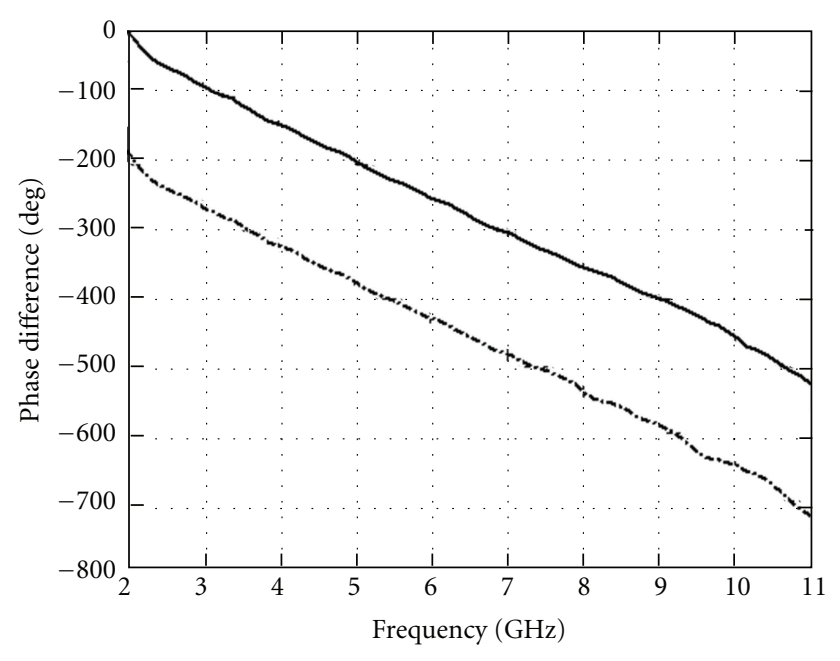

- Output port 2

-..- Output port 3

FIgURE 4: Measured output phase difference of the UWB Minkowski branch line coupler.

TABLE 3: Frequency and size comparison between $3 \mathrm{~dB}$ couplers and power dividers.

\begin{tabular}{lccc}
\hline $\begin{array}{l}\text { Reference } \\
\text { Number }\end{array}$ & $\begin{array}{c}\text { Frequency } \\
\text { Range [GHz }]\end{array}$ & $\begin{array}{c}\text { Size } \\
{[\mathrm{mm} \times \mathrm{mm}]}\end{array}$ & $\begin{array}{c}\text { Size } \\
(\text { Electrical })\end{array}$ \\
\hline$[1]$ & $3.1-10.6$ & $40 \times 50$ & $0.9 \lambda \times 1.1 \lambda$ \\
{$[2]$} & $3.1-10.6$ & $35 \times 50$ & $0.8 \lambda \times 1.1 \lambda$ \\
{$[5]$} & $3.1-10.6$ & $40 \times 50$ & $0.9 \lambda \times 1.1 \lambda$ \\
{$[6]$} & $3.1-10.6$ & Two $\times 20 \times 30$ & Two $\times 0.45 \lambda \times 0.7 \lambda$ \\
{$[7]$} & $3.1-10.6$ & Two $\times 20 \times 30$ & Two $\times 0.45 \lambda \times 0.7 \lambda$ \\
This work & $3.1-10.6$ & $30 \times 45$ & $0.7 \lambda \times 1.0 \lambda$ \\
\hline
\end{tabular}

on the results and could make the fabrication process more risky and challenging.

Electrical and mechanical size of some $3 \mathrm{~dB}$ couplers and power dividers are compared in Table 3 . All these references cover the UWB frequency range and this work has the smallest size and area.

The fabricated uniplanar coupler profile is shown in Figure 5. This optimized coupler has the overall size of 30 $\times 45 \mathrm{~mm}^{2}$ with $110 \%$ fractional bandwidth. The 4 th port of this coupler has to be terminated to a matched load. This coupler shows $180^{\circ}$ phase difference between output ports $\mathrm{P} 2$ and $\mathrm{P} 3$ with more than $10 \mathrm{~dB}$ isolation between them.

\section{Conclusion}

A $3 \mathrm{~dB}$ and $180^{\circ}$ fractal branch line coupler is designed, optimized, and fabricated. The Minkowski fractal geometry is used to make a small and single-layer microstrip pattern with overall size of $30 \times 45 \mathrm{~mm}^{2}$. This branch line coupler covers the ultrawideband frequency range with $110 \%$ fractional bandwidth. This optimized UWB coupler is fabricated and its insertion loss, return loss, and the output phase difference 


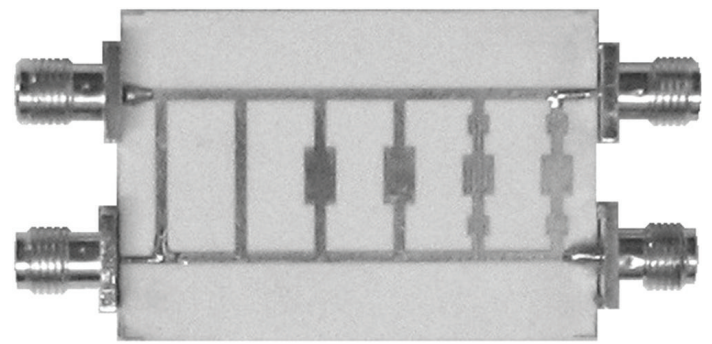

FIgURE 5: The fabricated profile of the UWB Minkowski branch line coupler.

have been measured, which showed a good agreement with the simulation results.

\section{Acknowledgment}

This work is published as a result of a research proposal named, "Design, Simulation, and Fabrication of a High Efficient LDMOS Power Amplifier". This proposal is approved and sponsored by the Shahre-Qods Branch, Islamic Azad University.

\section{References}

[1] S. W. Wong and L. Zhu, "Ultra-wideband power divider with good in-band splitting and isolation performances," IEEE Microwave and Wireless Components Letters, vol. 18, no. 8, pp. 518-520, 2008.

[2] S. W. Wong and L. Zhu, "Ultra-wideband power dividers with good isolation and improved sharp roll-off skirt," IET Microwaves, Antennas and Propagation, vol. 3, no. 8, pp. 11571163, 2009.

[3] J. S. Lim, U. H. Park, Y. C. Jeong et al., "800-5000 MHz ultrawideband CPW balun," Electronics Letters, vol. 42, no. 18, p. 1037, 2006.

[4] A. H. Naghavi, M. Tondro-Aghmiyouni, M. Jahanbakht, and A. A. Lotfi Neyestanak, "Hybrid wideband microstrip Wilkinson power divider based on lowpass filter optimized using particle swarm method," Journal of Electromagnetic Waves and Applications, vol. 24, no. 14-15, pp. 1877-1886, 2010.

[5] M. E. Bialkowski and A. M. Abbosh, "Design of a compact UWB out-of-phase power divider," IEEE Microwave and Wireless Components Letters, vol. 17, no. 4, pp. 289-291, 2007.

[6] A. M. Abbosh, "Ultra wideband inphase power divider for multilayer technology," IET Microwaves, Antennas and Propagation, vol. 3, no. 1, pp. 148-153, 2009.

[7] T. W. Eubanks and K. Chang, "Low-loss ultra-wideband double-sided parallel-strip line transition and power divider," Electronics Letters, vol. 46, no. 1, pp. 93-94, 2010.

[8] K. Song and Q. Xue, "Novel ultra-wideband (UWB) multilayer slotline power divider with bandpass response," IEEE Microwave and Wireless Components Letters, vol. 20, no. 1, pp. 13-15, 2010.

[9] D. H. Werner and S. Ganguly, "An overview of fractal antenna engineering research," IEEE Antennas and Propagation Magazine, vol. 45, no. 1, pp. 38-57, 2003. 

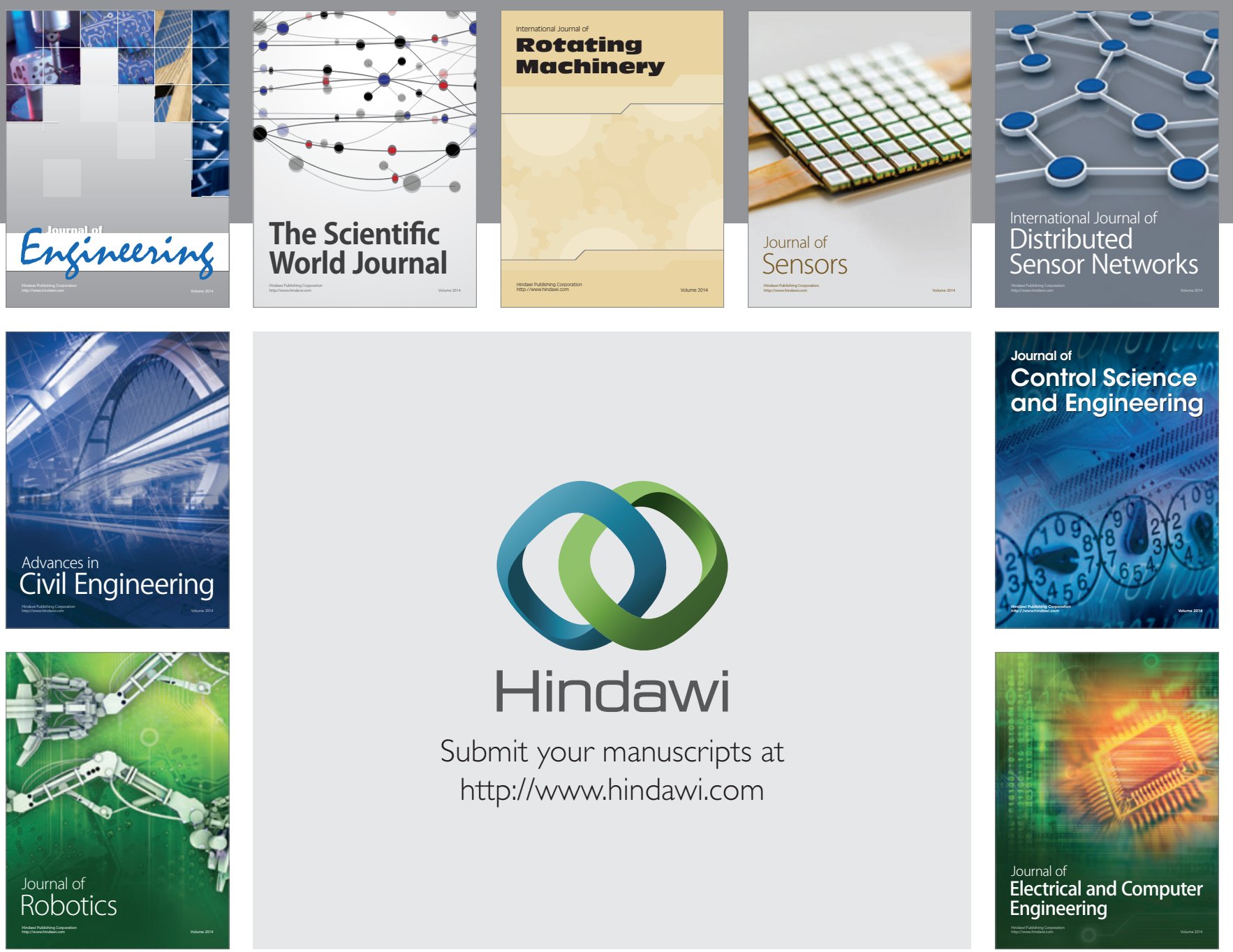

Submit your manuscripts at

http://www.hindawi.com
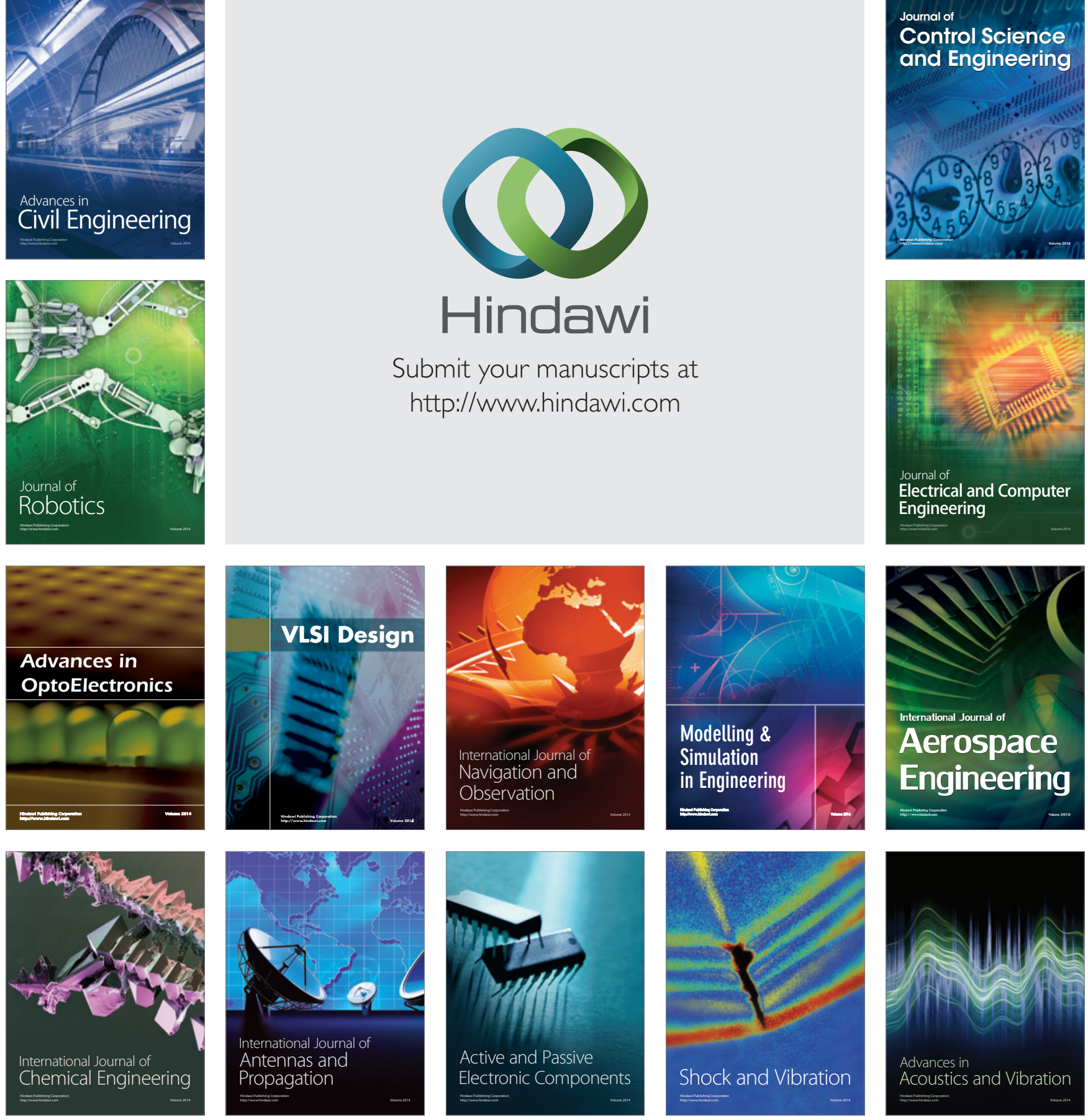